\title{
DYNAMIC ANALYSIS OF THE STANDARD OF LIVING AND THE QUALITY OF LIFE OF THE REGIONAL POPULATION USING THE EXAMPLE OF FEDERAL DISTRICTS ${ }^{1}$
}

\author{
Elena A. Berezovskaya \\ Southern Federal University, Rostov-on-Don, Russian Federation \\ Sergey V. Kryukov \\ Southern Federal University, Rostov-on-Don, Russian Federation
}

\begin{abstract}
To assess the consequences of the socio-economic policy implemented in the region, it is necessary to be able to evaluate the standard of living and the quality of life of the population not only in statics, but also in dynamics. At some point, the region may not be in the best situation in terms of the standard of living and the quality of life of the population, but if it demonstrates "movement" in the right direction for several years, it can be the basis for a positive assessment of the socio-economic policy implemented in the region. The authors have developed an approach to the dynamic analysis of the trajectory of "movement" of a region in the two-dimensional space "standard of living - quality of life". The researchers propose to use the minimum number of special selected indicators to improve the objectivity of assessing the standard of living and the quality of life of the regional population. To assess the standard of living of the regional population, the indicator "average per capita income of the population" is selected, and to assess the quality of life of the population, the indicator "life expectancy at birth" is selected. The authors propose to use not absolute values of indicators, but their ratio to the average Russian value of the same indicator in a given year in order to provide a common base for comparing regions on indicators that reflect the standard of living and the quality of life of the regional population for several years. We can judge the success of the socio-economic policy in the region during the analyzed period according to the trajectory of the region's movement in the space "standard of living - quality of life". The authors present the results of testing the proposed approach on the example of analyzing trajectories of "movement" of the Federal districts of the Russian Federation in the space "standard of living - quality of life" for the period 2005-2017.

Key words: standard of living, quality of life, incomes of the population, life expectancy, region, federal district, dynamic analysis, two-dimensional space, socio-economic policy.

Citation. Berezovskaya E.A., Kryukov S.V. Dynamic Analysis of the Standard of Living and the Quality of Life of the Regional Population Using the Example of Federal Districts. Journal of Volgograd State University. Economics, 2019, vol. 21, no. 4, pp. 79-89. (in Russian). DOI: https://doi.org/10.15688/ek.jvolsu.2019.4.8
\end{abstract}

УДК 330.59

ББК 65.9 (2Poc)-94
Дата поступления статьи: 29.07.2019

Дата принятия статьи: 02.09.2019

\section{ДИНАМИЧЕСКИЙ АНАЛИЗ УРОВНЯ И КАЧЕСТВА ЖИЗНИ НАСЕЛЕНИЯ РЕГИОНОВ НА ПРИМЕРЕ ФЕДЕРАЛЬНЫХ ОКРУГОВ ${ }^{1}$}

\author{
Елена Александровна Березовская \\ Южный федеральный университет, г. Ростов-на-Дону, Российская Федерация \\ Сергей Владимирович Крюков \\ Южный федеральный университет, г. Ростов-на-Дону, Российская Федерация
}

Аннотация. Для анализа последствий проводимой в регионе социально-экономической политики необходимо оценивать уровень и качество жизни населения не только в статике, но и в динамике. 
В какой-то момент регион может оказаться не в лучшем положении с точки зрения уровня и качества жизни населения, но если он демонстрирует в течение нескольких лет «движение» в правильном направлении, то это может стать основой для положительной оценки социально-экономической политики, проводимой в регионе. Авторами разработан подход к проведению динамического анализа траектории «перемещения» региона в двумерном пространстве «уровень жизни - качество жизни». Предложено использовать минимальное количество специально отобранных показателей для повышения объективности оценок уровня и качества жизни населения региона. Для оценки уровня жизни населения региона выбран показатель «среднедушевые доходы населения», а для оценки качества жизни населения выбран показатель «ожидаемая продолжительность жизни при рождении». Авторы предложили использовать не абсолютные значения показателей, а их отношение к среднероссийскому значению одного и того же показателя в данном году, чтобы обеспечить общую базу для сравнения регионов по показателям, отражающим уровень и качество жизни населения региона в течение нескольких лет. Об успешности социально-экономической политики в регионе в анализируемый период можно судить по траектории движения региона в пространстве «уровень жизни - качество жизни». Представлены результаты апробации предлагаемого подхода на примере анализа траекторий «движения» федеральных округов Российской Федерации в пространстве «уровень жизни - качество жизни» за период 2005-2017 годы.

Ключевые слова: уровень жизни, качество жизни, денежные доходы населения, ожидаемая продолжительность жизни, регион, федеральный округ, динамический анализ, двумерное пространство, социальноэкономическая политика.

Цитирование. Березовская Е. А., Крюков С. В. Динамический анализ уровня и качества жизни населения регионов на примере федеральных округов // Вестник Волгоградского государственного университета. Экономика. -2019. - Т. 21, № 4. - C. 79-89. - DOI: https://doi.org/10.15688/ek.jvolsu.2019.4.8

\section{Постановка проблемы}

Точная и своевременная информация о фактическом состоянии и динамике изменения уровня и качества жизни населения региона важна и для региональных органов власти, и для представителей бизнес-сообщества, и для широких кругов населения. Поскольку подобная информация появляется из разных источников - как государственных (Росстат), так и негосударственных (рейтинговые агентства, исследовательские центры и т. п.) - и часто является довольно противоречивой, возникает задача формирования непротиворечивого и доказательного подхода к оценке уровня и качества жизни населения региона. Очень часто понятия уровень и качество жизни употребляют как синонимы, одни и те же показатели используют для объяснения роста (или снижения) как уровня, так и качества жизни населения региона [Управление качеством жизни..., 2019; Колмакова и др., 2017; Овсянникова, 2018; Юзбеков и др., 2014]. Подобная нечеткость в определениях и методике оценки уровня и качества жизни населения региона приводит либо к ошибочному ранжированию регионов и, соответственно, к неправильным выводам о реальном положении дел, либо позволяет манипулировать оценочными данными и подгонять их под нужный результат.

Почему появляются ошибки либо возможность манипулирования конечными оценками уровня и качества жизни населения? Большинство исследователей следуют идее, что уровень и качество жизни - это настолько многогранные понятия, которые можно описать, измерить и оценить только с привлечением десятков разнообразных показателей. Организация Объединенных Наций утвердила перечень из двенадцати групп индикаторов для оценки уровня жизни населения в той или иной стране, в каждой группе может быть десять и более конкретных показателей [Уровень жизни...]. В США был составлен «Рейтинг лучших стран 2019 года», сформированный в партнерстве BAV Group подразделением глобальной маркетинговой коммуникационной компании VMLY\&R и школой Уортона Университета Пенсильвании. Данный рейтинг основан на исследовании, в ходе которого было опрошено более 20000 граждан из четырех макрорегионов мира, чтобы оценить их восприятие 80 стран по 75 различным показателям [Quality of Life]. Рейтинговое агентство РИА «Рейтинг» медиагруп- 
пы МИА «Россия сегодня» регулярно составляет рейтинг регионов России по уровню жизни по более чем 70 показателям [Рейтинг регионов...].

Для обеспечения сравнения объектов (например, регионов) по уровню и (или) качеству жизни необходимо агрегировать десятки показателей, прибегая к нормированию показателей, введению весовых коэффициентов, выбору формул осреднения. Например, правило «мажорантности средних» говорит о том, что для одного и того же набора исходных данных мы совершенно точно получим четыре разных значения, если применим разные формулы осреднения данных: среднеквадратичное, среднеарифметическое, среднегеометрическое и среднегармоничное [Средние величины...]. Чем больше манипуляций проделывают с исходными данными, тем выше вероятность появления ошибок и тем больше возможностей для «подгонки» конечных оценок под нужный результат.

Даже те исследователи, которые, например, признают денежные доходы населения в качестве универсальной характеристики уровня жизни населения, также используют для получения конечных оценок несколько различных показателей, характеризующих денежные доходы [Гришина и др., 2019].

Результаты наших исследований, которые позволили сделать вывод о необходимости нахождения минимального набора объективных показателей, способных отразить уровень и качество жизни населения региона, опубликованы ранее [Крюков, 2018]. Таким показателем, по нашему мнению, для отражения уровня жизни может быть «среднедушевые денежные доходы населения региона», а для отражения качества жизни «ожидаемая продолжительность жизни при рождении».

\section{Информация и методы}

В основе предлагаемого подхода лежит идея отражать изменение во времени социально-экономического положения региона в двумерном пространстве, где по осям расположены показатели, характеризующие уровень и качество жизни населения региона.
В качестве источника первичной информации для проведения расчетов были использованы статистические данные из официального сборника Росстата [Регионы России..., 2018] за 2005-2017 годы.

Для того чтобы привести исходные данные по регионам в сопоставимый вид, показатели, отражающие уровень и качество жизни населения региона, были нормированы по отношению к среднероссийским значениям этих показателей в конкретном году. Благодаря такому нормированию удалось избежать необходимости учитывать уровень инфляции при сопоставлении среднедушевых доходов населения региона в разные годы. Кроме того, подобное нормирование позволяет учесть не просто достижения региона в повышении уровня и качества жизни населения, но и оценить эти успехи (или неудачи) на фоне средних показателей по Российской Федерации. Если региональные власти добились повышения показателей уровня и качества жизни населения региона в абсолютном выражении, но отстали от других регионов по темпам роста, - это означает, что не полностью использован потенциал роста, а значит нужно искать способы ускорения темпов роста.

Итак, для формирования двумерного пространства, в котором можно будет отслеживать в динамике изменение положения регионов, были выбраны следующие показатели:

1) среднедушевые денежные доходы населения региона по отношению к среднедушевым денежным доходам населения Российской Федерации в данном году;

2) ожидаемая продолжительность жизни при рождении населения региона по отношению к ожидаемой продолжительности жизни при рождении населения Российской Федерации в данном году.

Движение точки, отражающей положение региона в двумерном пространстве, вправо и вверх будет свидетельствовать о повышении уровня и качества жизни населения данного региона. Движение точки (региона) в любом другом направлении будет служить сигналом о необходимости активизации действий в направлении повышения уровня и (или) качества жизни населения региона. 


\section{Динамический анализ уровня \\ и качества жизни населения федеральных округов РФ}

Далее будут представлены рисунки, отражающие «путь» каждого федерального округа, пройденный за период 2005-2017 гг. в пространстве «уровень жизни - качество жизни». Для сравнения на каждом рисунке будет отражена позиция Российской Федерации в данном пространстве. Точка, характеризующая позицию Российской Федерации на каждом рисунке, будет иметь координаты $(100,100)$. Для удобства понимания начальная точка «пути» каждого федерального округа (2005 г.) будет иметь увеличенный размер.

На рисунке 1 представлены «пути» движения всех восьми федеральных округов РФ за 2005-2017 годы. Увеличенная точка с координатами $(100,100)$ отражает средние данные по уровню и качеству жизни по Российской Федерации.

Первое, что бросается в глаза, - это перемещение каждого федерального округа в своем локальном пространстве, практически не пересекающемся с подобными пространствами других округов. Это говорит о том, что все федеральные округа по уровню и качеству жиз- ни населения отличаются друг от друга, и то, что может быть успешно реализовано в этой сфере в одном округе, совершенно не обязательно будет таким же успешным в других округах - нужен дифференцированный подход.

Также по рисунку 1 мы можем определить, что превышен среднероссийский уровень жизни в таких округах, как Дальневосточный, Уральский, Северо-Западный и Центральный, а по качеству жизни превышен среднероссийский уровень в таких округах, как Северо-Западный, Центральный, Южный и Северо-Кавказский. Таким образом, только два округа превышают среднероссийские показатели одновременно и по уровню и качеству жизни - Северо-Западный и Центральный. Последний за весь период 20052017 гг. является несомненным «чемпионом» по уровню и качеству жизни населения. Дополнительный анализ динамики изменения положения каждого округа в пространстве «уровень жизни - качество жизни» за анализируемый период позволяет получить еще целый ряд интересных заключений.

На рисунке 2 представлен «путь» Дальневосточного федерального округа в пространстве «уровень жизни - качество жизни» за 2005-2017 годы.

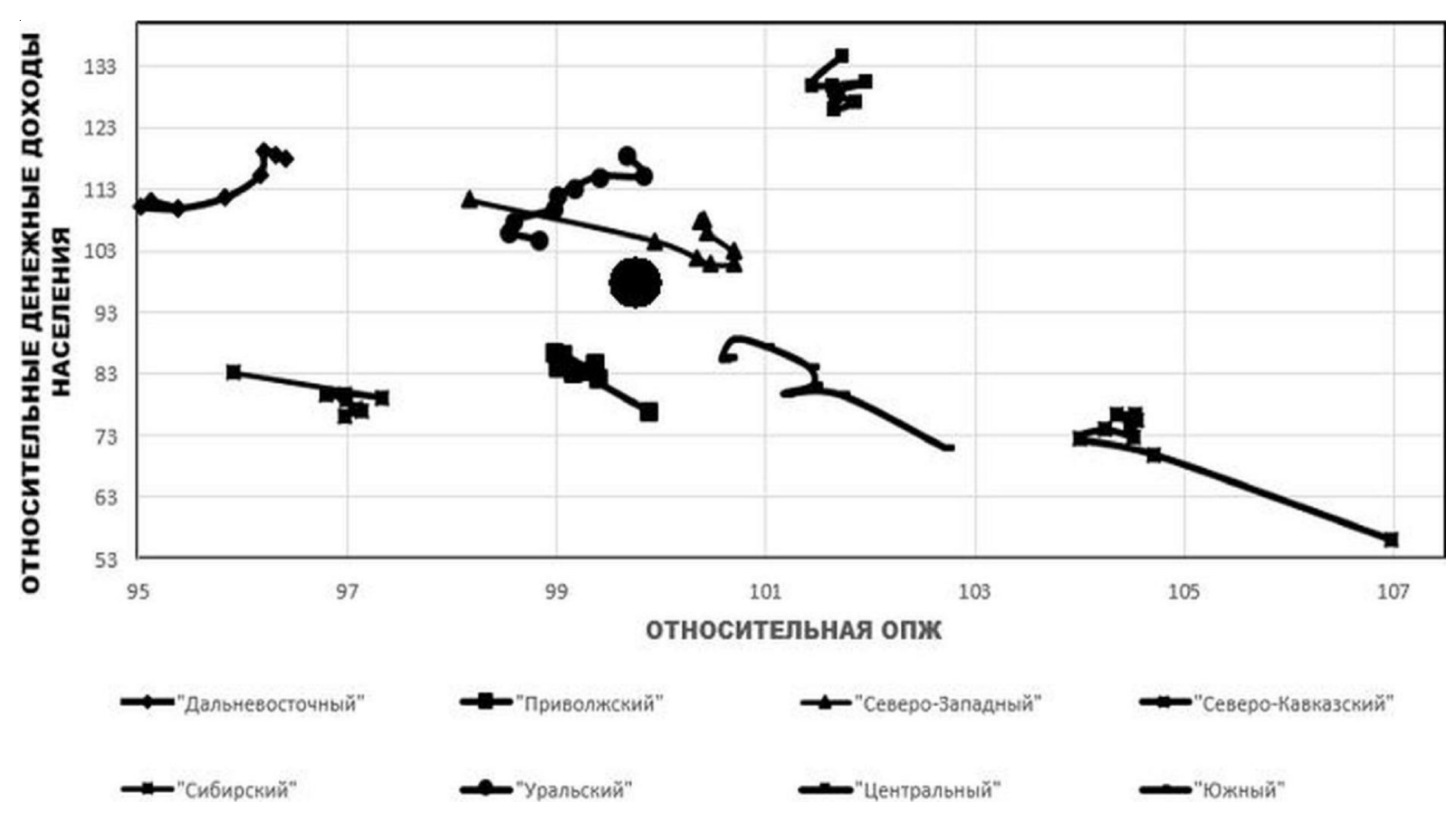

Рис. 1. Динамика перемещения федеральных округов РФ в пространстве «уровень жизни - качество жизни» за 2005-2017 годы 
E.A. Березовская, C.В. Крюков. Динамический анализ уровня и качества жизни населения регионов

За анализируемый период Дальневосточный федеральный округ единственный продемонстрировал положительную динамику и по уровню, и по качеству жизни населения региона, имея в настоящее время чуть худшие результаты по качеству жизни относительно среднероссийских показателей и на 18 \% опережая среднероссийские показатели по уровню жизни. Следует изучить опыт регионов, входящих в Дальневосточный федеральный округ, который позволил обеспечить уникаль- ный рост одновременно и уровня, и качества жизни населения округа особенно в период 2011-2015 годов.

Рассмотрим пример округа, который за тот же период 2005-2017 гг. проделал «путь», противоположный по направлению тому, что прошел Дальневосточный федеральный округ. На рисунке 3 представлен «путь» Уральского федерального округа в пространстве «уровень жизни - качество жизни» за этот период.

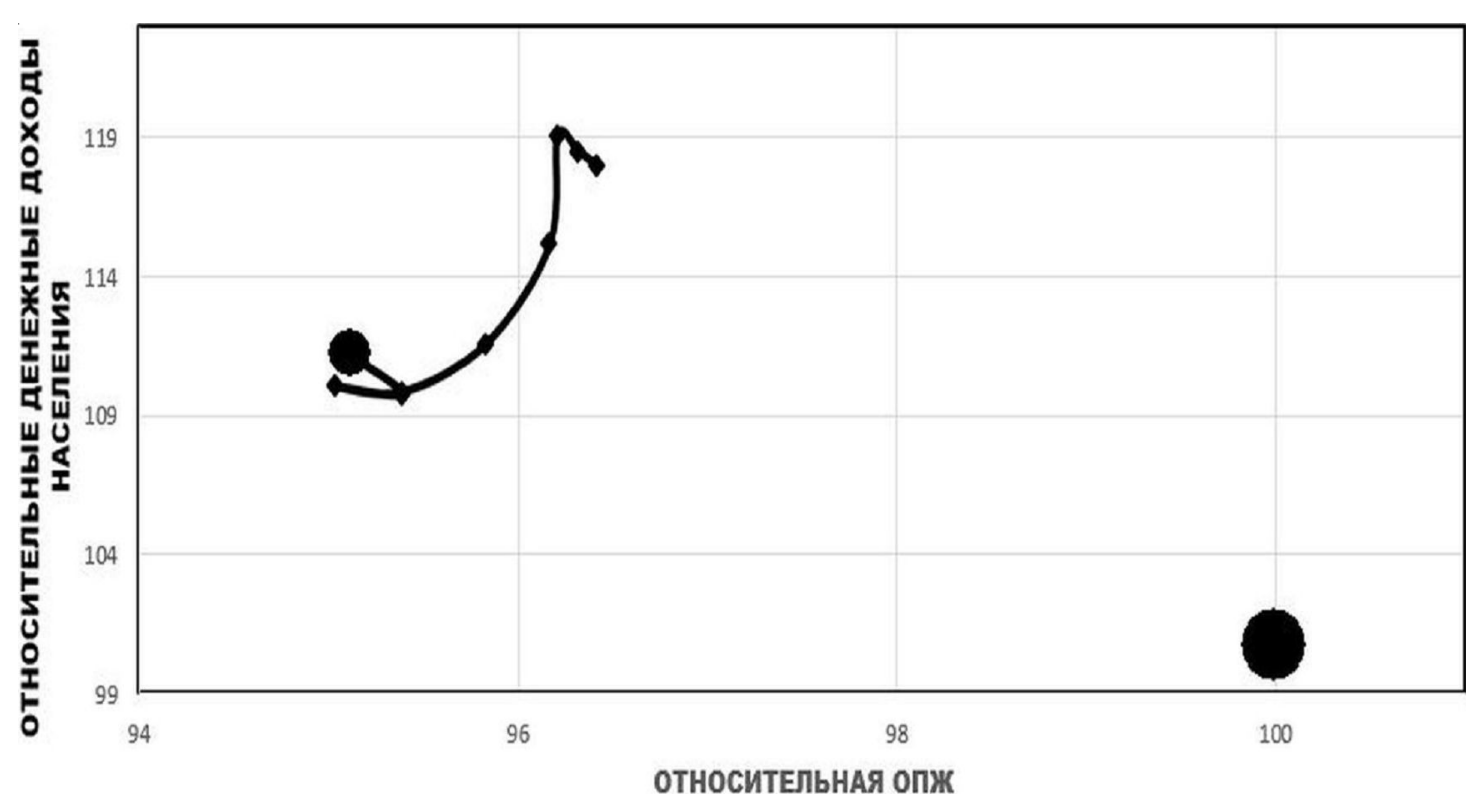

Рис. 2. Динамика перемещения Дальневосточного федерального округа РФ в пространстве «уровень жизни - качество жизни» за период 2005-2017 годов

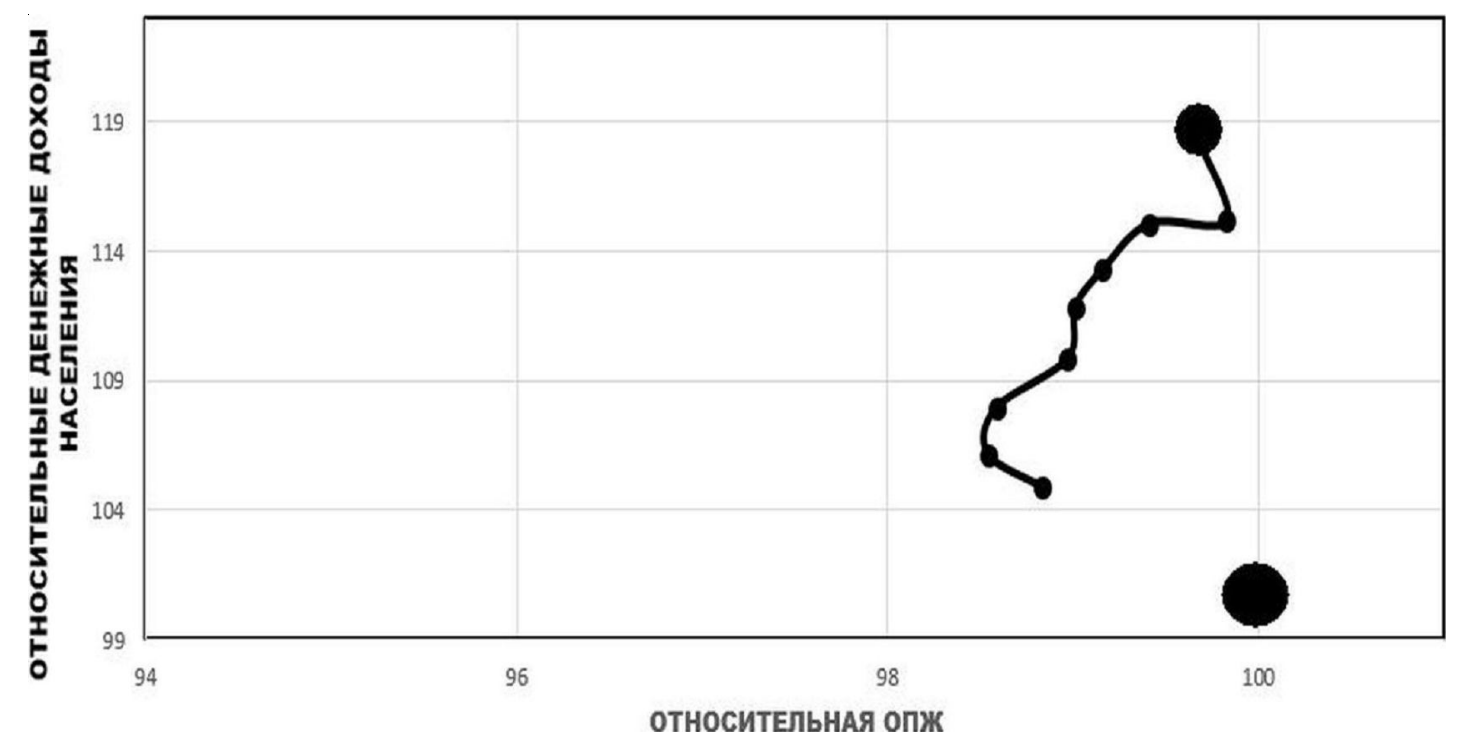

Рис. 3. Динамика перемещения Уральского федерального округа РФ в пространстве «уровень жизни - качество жизни» за 2005-2017 годы 
В 2010-2016 гг. в Уральском федеральном округе ежегодно снижались и уровень, и качество жизни населения относительно среднероссийских показателей. Такой негативный опыт также должен быть подвержен более глубокому анализу, поскольку в данный временной период он является уникальным. Нельзя сослаться на то, что по всей стране ухудшились условия повышения уровня и качества жизни населения, лучше ничего нельзя было сделать. Данные по другим округам показывают, что можно было сделать лучше, если не по двум направлениям, то хотя бы по одному.

Далее рассмотрим три федеральных округа с похожими траекториями движения в пространстве «уровень жизни - качество жизни» 2005-2017 гг., где одновременно наблюдаются рост уровня жизни и снижение качества жизни.

На рисунке 4 представлен «путь» Северо-Кавказского федерального округа в пространстве «уровень жизни - качество жизни» за 2005-2017 годы.

Основной период одновременного роста уровня и снижения качества жизни для Северо-Кавказского округа приходится на 20052011 гг., после чего начинается период «топтания на месте». Хорошо, что удалось в период 2012-2016 гг. переломить тенденцию к снижению качества жизни, однако в округе необходимо произвести «перегруппировку сил» и найти способы перейти к позитивному росту в обоих направлениях, особенно в сфере повышения уровня жизни.

На рисунке 5 представлен «путь» Южного федерального округа в пространстве «уровень жизни - качество жизни» за период 2005-2017 годов.

Для Южного федерального округа в период 2005-2015 гг. (с небольшими исключениями) характерна траектория повышения уровня жизни при одновременном снижении качества жизни. В 2016-2017 гг. наметилась негативная тенденция к ухудшению и уровня, и качества жизни населения округа, которую удалось пока замедлить, но не переломить. В округе также необходимо изыскивать резервы, которые позволят выйти на новую позитивную траекторию развития.

На рисунке 6 представлен «путь» Приволжского федерального округа в пространстве «уровень жизни - качество жизни» за период 2005-2017 годов. Можно выделить два периода в динамике развития Приволжского федерального округа, характеризующихся противоположными тенденциями. Если в 2005-2014 гг. в округе происходил рост уровня жизни населения при одновременном снижении качества жизни, то после 2014 г. тренд сменился противоположным - происходит рост качества жизни при одновременном снижении уровня жизни. В данном округе необходимо изыскать пути повышения, в первую очередь, уровня жизни населения.

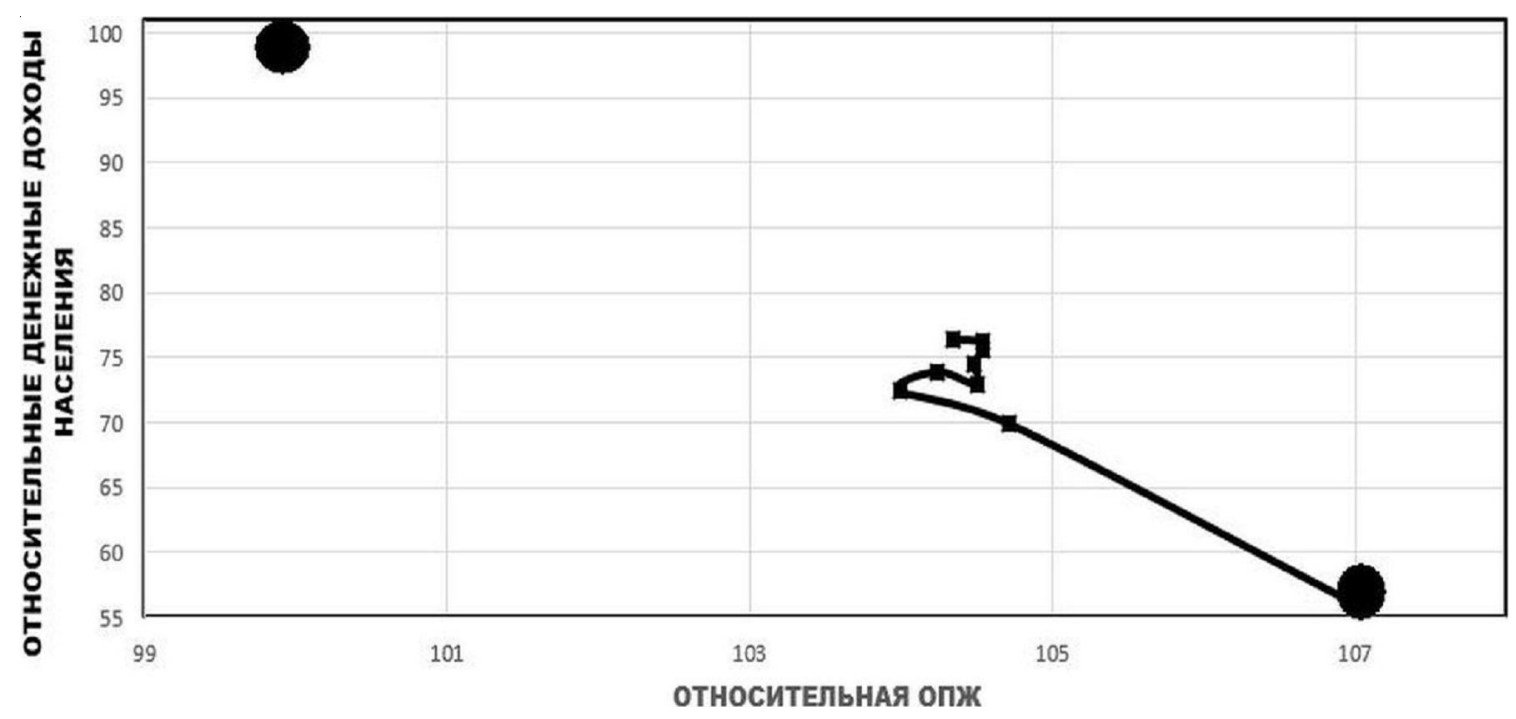

Рис. 4. Динамика перемещения Северо-Кавказского федерального округа РФ в пространстве «уровень жизни - качество жизни» за 2005-2017 годы 
E.A. Березовская, C.В. Крюков. Динамический анализ уровня и качества жизни населения регионов

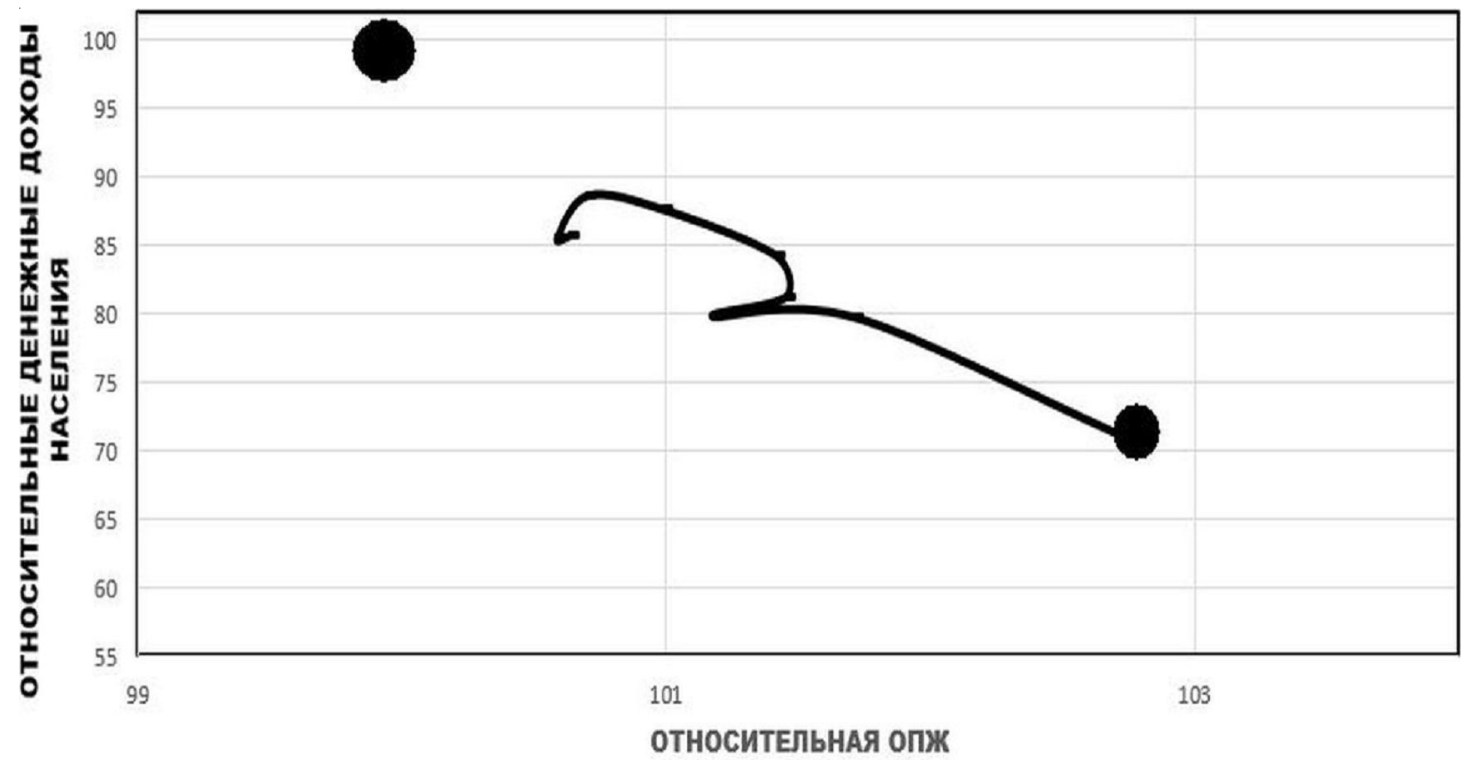

Рис. 5. Динамика перемещения Южного федерального округа РФ в пространстве «уровень жизни - качество жизни» за 2005-2017 годы

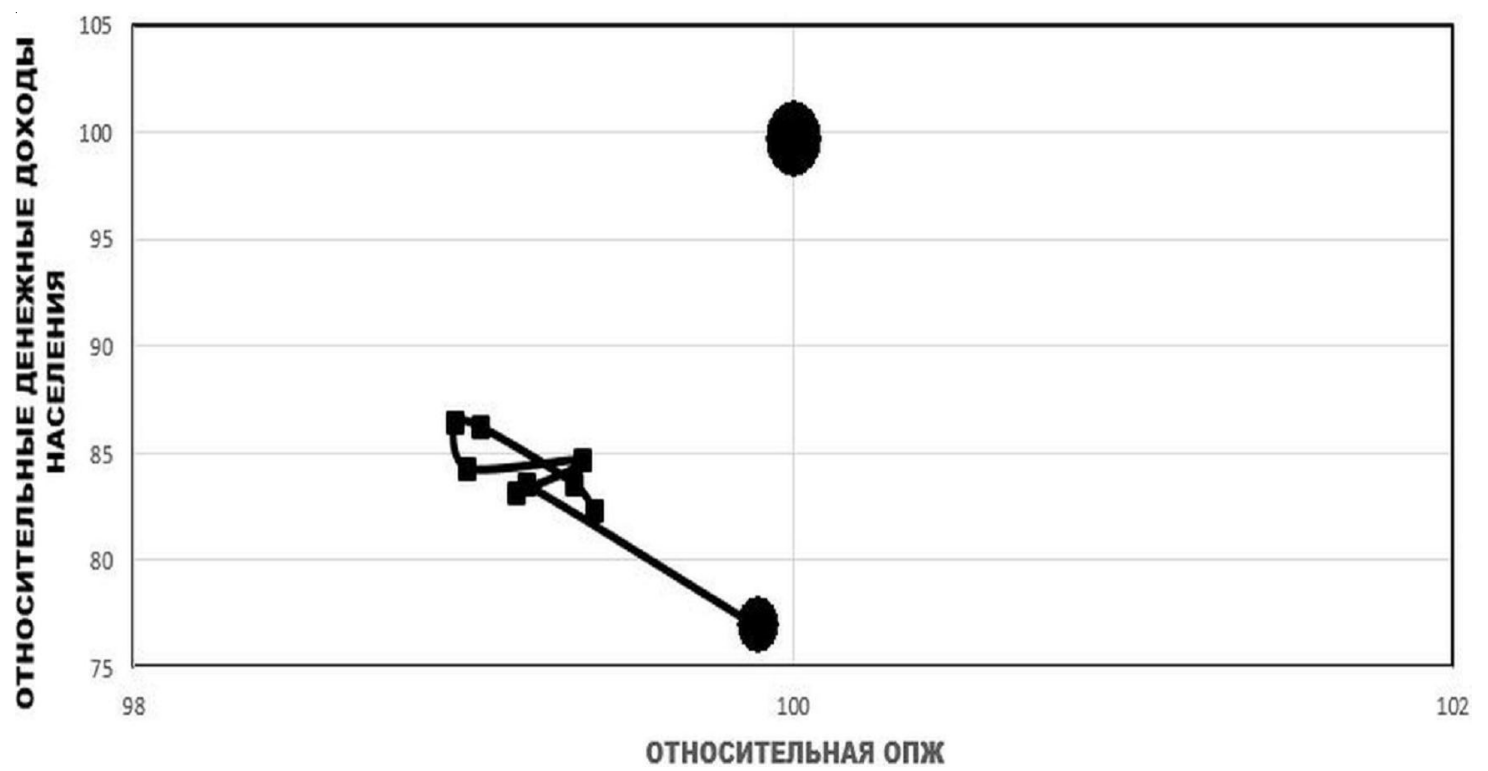

Рис. 6. Динамика перемещения Приволжского федерального округа РФ в пространстве «уровень жизни - качество жизни» за 2005-2017 годы

На рисунке 7 представлен «путь» Сибирского федерального округа в пространстве «уровень жизни - качество жизни» за период 20052017 гг., который относительно всех других округов находится в наиболее слабой позиции.

В 2005-2010 гг. в округе снижался уровень жизни населения, но все же происходил рост качества жизни. После 2010 г. динамику развития региона можно охарактеризовать как «топтание на месте» с тенденцией к ухудшению и уровня, и качества жизни населения округа. Требуется провести серьезную работу по поиску внутренних резервов и внешних возможностей, чтобы переломить негативную тенденцию в развитии округа.

На рисунке 8 представлен «путь» СевероЗападного федерального округа в пространстве «уровень жизни - качество жизни» за 20052017 гг., чьи показатели уровня и качества жизни наиболее близки к среднероссийским значениям.

Траектория движения Северо-Западного федерального округа практически повторяет траекторию движения Приволжского округа с точностью до наоборот. 


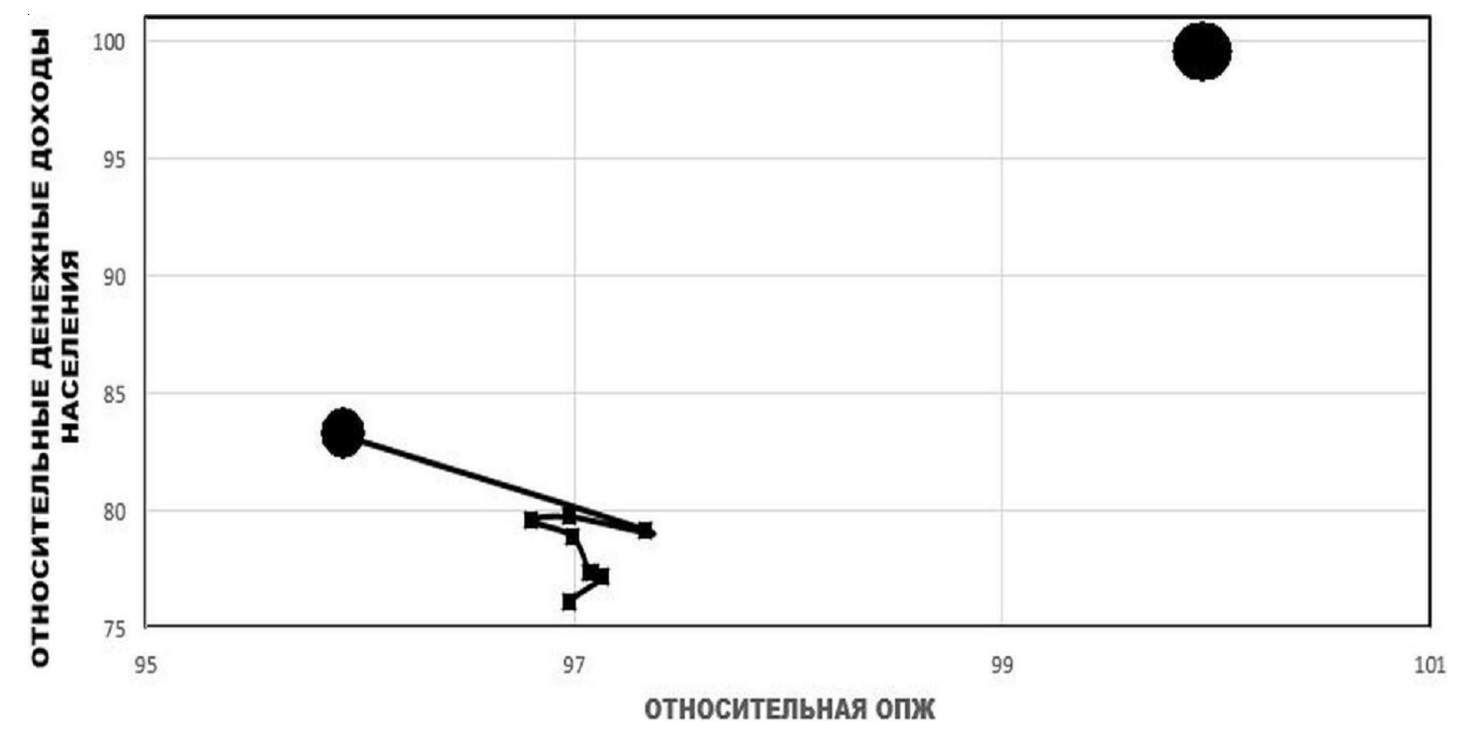

Рис. 7. Динамика перемещения Сибирского федерального округа РФ в пространстве «уровень жизни - качество жизни» за период 2005-2017 годов

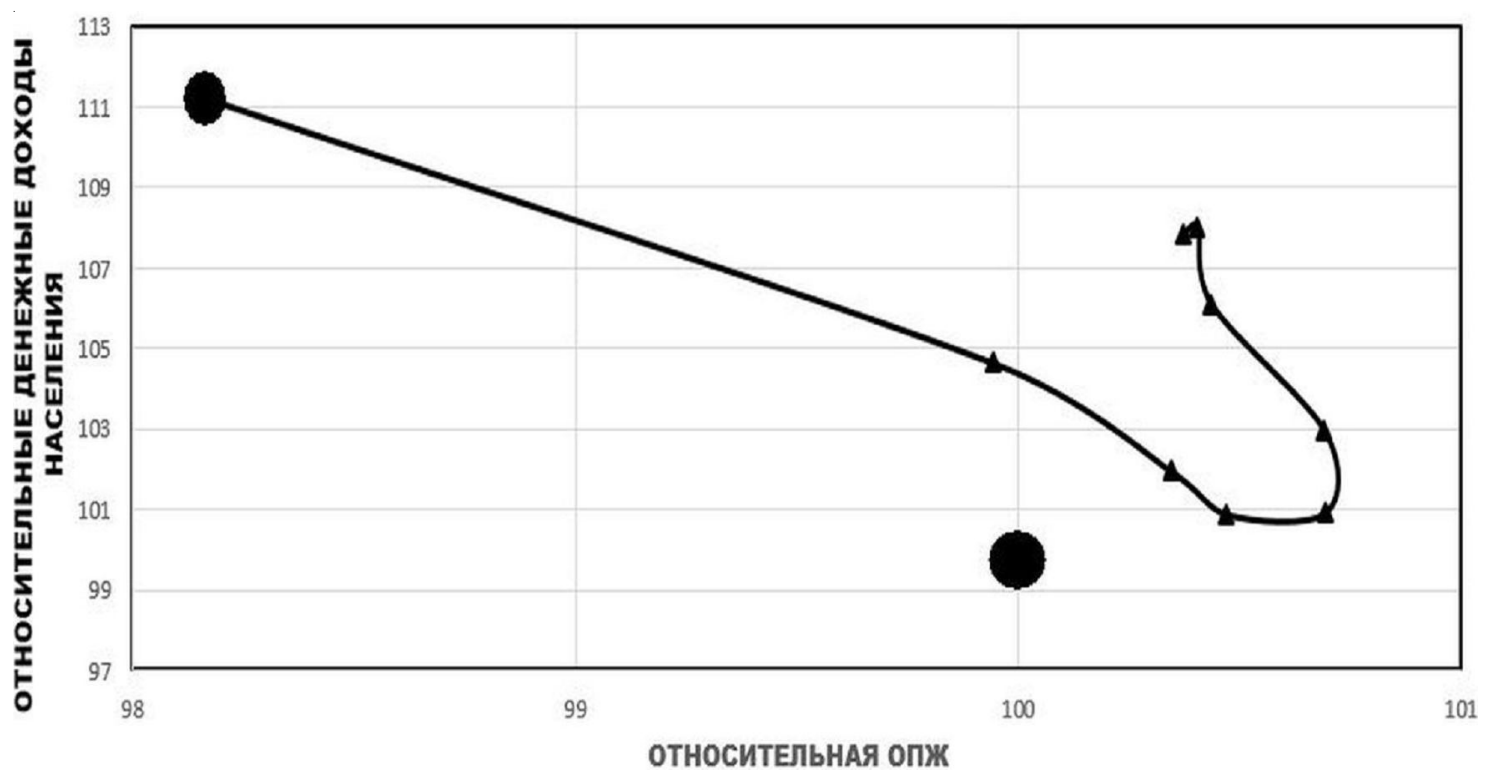

Рис. 8. Динамика перемещения Северо-Западного федерального округа РФ в пространстве «уровень жизни - качество жизни» за период 2005-2017 годов

В 2005-2013 гг. в округе наблюдается снижение уровня жизни населения при одновременном росте качества жизни. Однако после 2013 г. тренд движения меняется на противоположный - уровень жизни начинает расти, а качество жизни - падать. Именно на факторы, способствующие росту качества жизни населения, следует в первую очередь обратить внимание в СевероЗападном округе.

На рисунке 9 представлен «путь» Центрального федерального округа в пространстве «уровень жизни - качество жизни» за 2005-
2017 гг., несомненно, самого успешного округа с точки зрения достигнутых значений и уровня, и качества жизни населения.

Анализируя траекторию движения Центрального федерального округа в пространстве «уровень жизни - качество жизни» за период 2005-2017 гг., нельзя согласиться с выводом о его лидерских позициях. Эффект «топтания на месте» свидетельствует об отсутствии четкой, продуманной стратегии вывода округа на позитивную траекторию повышения уровня и качества жизни населения. 
E.A. Березовская, C.В. Крюков. Динамический анализ уровня и качества жизни населения регионов

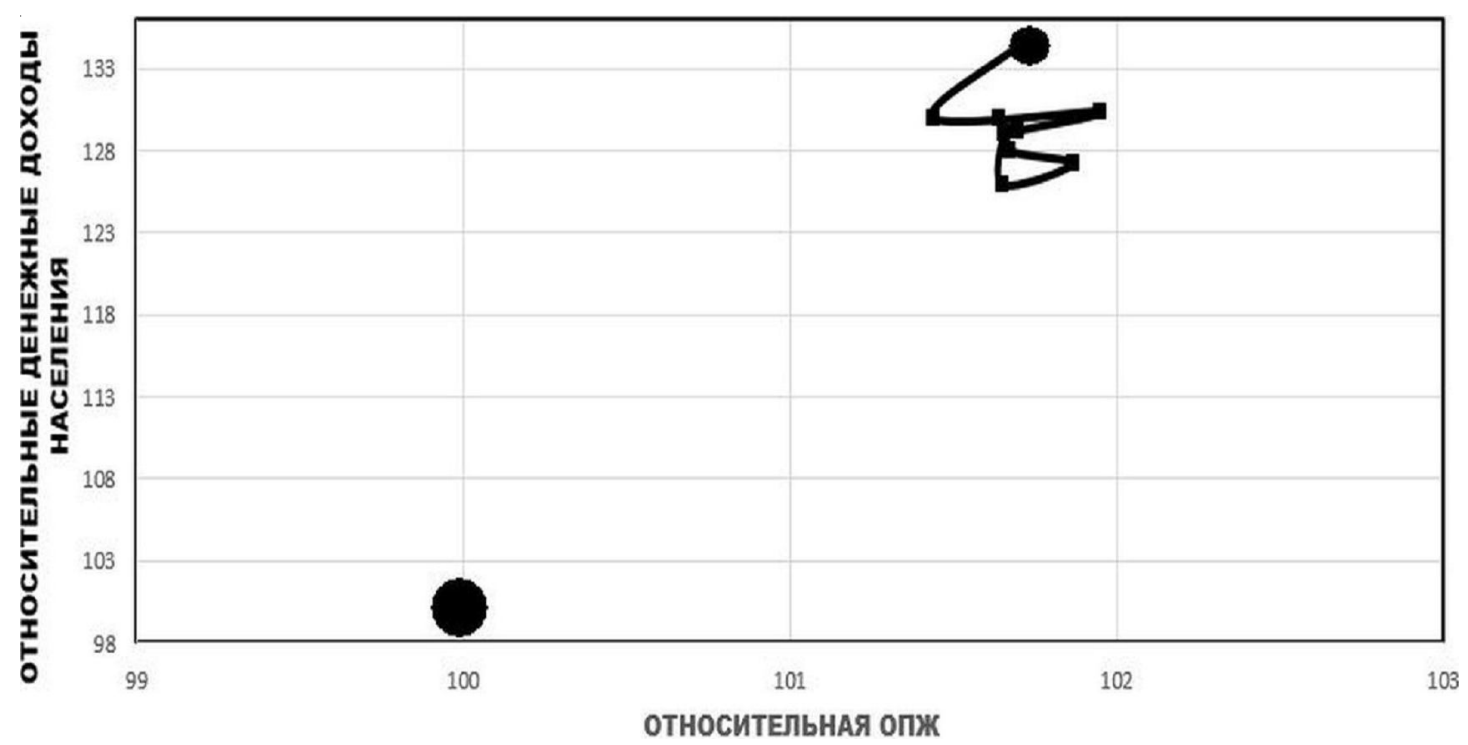

Рис. 9. Динамика перемещения Центрального федерального округа РФ в пространстве «уровень жизни - качество жизни» за период 2005-2017 гг.

\section{Выводы и рекомендации}

Использование в качестве основы для определения уровня и качества жизни населения региона минимального количества объективных показателей, отслеживаемых Росстатом, позволит избежать, с одной стороны, ошибок в интерпретации оценок уровня и качества жизни населения региона, а с другой - возможности манипуляции данными при получении подобных оценок.

Предложенный подход к проведению динамического анализа уровня и качества жизни населения регионов в разрезе федеральных округов позволяет выявить разные сценарии развития территориальных образований и сформулировать рекомендации по совершенствованию уровня и качества жизни населения в этих регионах.

\section{ПРИМЕЧАНИЕ}

${ }^{1}$ Исследование выполнено при финансовой поддержке РФФИ в рамках научного проекта № 18-010-00806 «Уровень жизни населения административно-территориальных образований: выявление, исследование, анализ и оценка значимости определяющих факторов (для последующей оптимизации в условиях ограниченных ресурсов)».

The reported study was funded by RFBR, research project no. 18-010-00806 "Living Standards of the Population of Administrative-Territorial Units:
Identification, Research, Analysis and Evaluation of the Significance of the Determining Factors (For Further Optimization in Resource-Limited Conditions)".

\section{СПИСОК ЛИТЕРАТУРЫ}

Гришина, Е. Н. Денежные доходы как основной индикатор уровня жизни населения России / Е. Н. Гришина, И. П. Лаптева, Л. Н. Трусова // Статистика и экономика. - 2019. - Т. 16, № 3. - С. 15-23.

Колмакова, И. Д. Экономико-математические методы в оценке и планировании уровня жизни населения региона / И. Д. Колмакова, Е. И. Байкова, Е. М. Колмакова // Региональная экономика: теория и практика. - 2017. - № 5. - С. 928-936.

Крюков, С. В. Сравнительная оценка регионов РФ по уровню и качеству жизни населения / С. В. Крюков // Государственное и муниципальное управление. Ученые записки. 2018. - № 3. - С. 22-29.

Овсянникова, Р. В. Кластерный анализ в оценке уровня и качества жизни населения субъектов РФ / Р. В. Овсянникова // Вестник Самарского государственного экономического университета. - 2018. - № 1. - С. 38-45.

Регионы России. Социально-экономические показатели. 2018 : Стат. сб. - М. : Росстат, 2018. $1162 \mathrm{c}$.

Рейтинг регионов России по уровню жизни. - Электрон. текстовые дан. - Режим доступа: https:// basetop.ru/rejting-regionov-rossii-po-urovnyuzhizni-2019 (дата обращения: 15.07.2019). - Загл. с экрана. 
Средние величины. - Электрон. текстовые дан. Режим доступа: http://www.grandars.ru/ student/statistika/srednie-velichiny.html (дата обращения: 15.07.2019). - Загл. с экрана.

Управление качеством жизни населения в регионах России / Р. В. Губарев [и др.] // Journal of Institutional Studies. - 2019. - № 11 (2). - C. 146170. - DOI: https://doi.org/10.17835/20766297.2019.11.2.146-170.

Уровень жизни в России и странах мира в 2019 году. Электрон. текстовые дан. - Режим доступа: http://finansiko.ru/uroven_zhizni naseleniya_rossii_stran_mira (дата обращения: 15.07.2019). - Загл. с экрана.

Юзбеков, М. А. Комплексная оценка качества жизни населения в регионе / М. А. Юзбеков, А. К. Юзбеков // Фундаментальные исследования. - 2014. - № 3, ч. 2. - С. 349-355.

Quality of Life. - Electronic text data. - Mode of access: https://www.usnews.com/news/best-countries/ quality-of-life-rankings (date of access: 15.07.2019). - Title from screen.

\section{REFERENCES}

Grishina E.N., Lapteva I.P., Trusova L.N. Denezhnye dokhody kak osnovnoy indikator urovnya zhizni naseleniya Rossii [Cash Income as the Main Indicator of Living Standards of the Russian Population]. Statistika i ekonomika [Statistics and Economics], 2019, vol. 16, no. 3, pp.15-23.

Kolmakova I.D., Baykova E.I., Kolmakova E.M. Ekonomiko-matematicheskie metody v otsenke i planirovanii urovnya zhizni naseleniya regiona [Economic and Mathematical Methods in Assessing and Planning the Standard of Living of the Population of the Region]. Regionalnaya ekonomika: teoriya i praktika [Regional Economics: Theory and Practice], 2017, no. 5, pp. 928-936.

Kryukov S.V. Sravnitelnaya otsenka regionov RF po urovnyu i kachestvu zhizni naseleniya [Comparative Assessment of Russian Regions on the Standard of Living and Quality of Life].
Gosudarstvennoe i munitsipalnoe upravlenie. Uchenye zapiski [State and Municipal Management. Scholar Notes], 2018, no. 3, pp. 22-29.

Ovsyannikova R.V. Klasternyy analiz v otsenke urovnya i kachestva zhizni naseleniya subyektov RF [Cluster Analysis in Assessing the Standard of Living and Quality of Life of the Population of Subjects of the Russian Federation]. Vestnik Samarskogo gosudarstvennogo ekonomicheskogo universiteta [Vestnik of Samara State University of Economics], 2018, no. 1, pp. 38-45.

Regiony Rossii. Sotsialno-ekonomicheskie pokazateli. 2018: Stat. sb. [Regions of Russia. Socio-Economic Indicators. Statistical Compilation]. Moscow, Rosstat, 2018. 1162 p.

Reyting regionov Rossii po urovnyu zhizni [Rating of Regions of Russia in Terms of the Standard of Living]. URL: https://basetop.ru/rejtingregionov-rossii-po-urovnyu-zhizni-2019 (accessed 15 July 2019).

Srednie velichiny [Average Values]. URL: http:// www.grandars.ru/student/statistika/srednievelichiny.html (accessed 15 July 2019).

Gubarev R.V., Dzyuba E.I., Kulikova O.M., Fayzullin F.S. Upravlenie kachestvom zhizni naseleniya $\mathrm{v}$ regionakh Rossii [Quality of Life Management in Russian Regions]. Journal of Institutional Studies, 2019, no. 11 (2), pp. 146170. DOI: 10.17835/2076-6297.2019.11.2.146-170.

Uroven zhizni v Rossii i stranakh mira v 2019 godu [Living Standards in Russia and the World in 2019]. URL: http://finansiko.ru/uroven_zhizni_ naseleniya_rossii_stran_mira (accessed 15 July 2019).

Yuzbekov M.A., Yuzbekov A.K. Kompleksnaya otsenka kachestva zhizni naseleniya $\mathrm{v}$ regione [Comprehensive Assessment of the Quality of Life of the Population in the Region]. Fundamentalnye issledovaniya [Fundamental Research], 2014, no. 3, part 2, pp. 349-355.

Quality of Life. URL: https://www.usnews.com/news/ best-countries/quality-of-life-rankings (accessed 15 July 2019). 
E.A. Березовская, C.В. Крюков. Динамический анализ уровня и качества жизни населения регионов

\section{Information About the Authors}

Elena A. Berezovskaya, Candidate of Sciences (Economics), Associate Professor, Department of Economic Cybernetics, Southern Federal University, B. Sadovaya St., 105/42, 344006 Rostov-onDon, Russian Federation, berezovskaya@sfedu.ru, https://orcid.org/0000-0003-3756-6596

Sergey V. Kryukov, Doctor of Sciences (Economics), Professor, Head of the Department of Economic Cybernetics, Southern Federal University, B. Sadovaya St., 105/42, 344006 Rostov-on-Don, Russian Federation, svkrukov@sfedu.ru, https://orcid.org/0000-0003-4736-7697

\section{Информация об авторах}

Елена Александровна Березовская, кандидат экономических наук, доцент кафедры экономической кибернетики, Южный федеральный университет, ул. Большая Садовая, 105/42, 344006 г. Ростовна-Дону, Российская Федерация, berezovskaya@sfedu.ru, https://orcid.org/0000-0003-3756-6596

Сергей Владимирович Крюков, доктор экономических наук, профессор, заведующий кафедрой экономической кибернетики, Южный федеральный университет, ул. Большая Садовая, 105/42, 344006 г. Ростов-на-Дону, Российская Федерация, svkrukov@sfedu.ru, https://orcid.org/0000-0003-4736-7697 